\title{
AutoSet nasal CPAP titration: constancy of pressure, compliance and effectiveness at 8 month follow-up
}

\author{
H. Teschler*, A.A. Farhat*, V. Exner*, N. Konietzko*, M. Berthon-Jones**
}

\begin{abstract}
AutoSet nasal CPAP titration: constancy of pressure, compliance and effectiveness at 8 month follow-up. H. Teschler, A.A. Farhat, V. Exner, N. Konietzko, M. Berthon-Jones. (C)ERS Journals Ltd 1997.

ABSTRACT: We have previously shown that AutoSet satisfactorily improves sleepdisordered breathing and sleep architecture in subjects with obstructive sleep apnoea (OSA) syndrome. The aim of this study was to determine, in subjects treated with long-term conventional fixed pressure continuous positive airway pressure (CPAP) at the AutoSet recommended pressure, whether: the long-term compliance is satisfactory; the improvement persists once initial rebound is over; the titration pressure is stable with time; and the titration pressure is comparable with manual titration pressure using a similar end-point.

Twenty males with OSA, previously studied with full polysomnography on their diagnostic night, at manual and AutoSet titration, and at the AutoSet recommended fixed pressure, were re-studied after a mean of 3 and 8 months of treatment at the recommended fixed pressure. Re-study included home respiratory monitoring (Nellcor EdenTrace ${ }^{\mathrm{TM}}$ ), and repeated manual and AutoSet titration with polysomnography. Compliance was assessed with hour-meter readings.

Mean $\left( \pm\right.$ SEM) usage was $5.7 \pm 0.1 h^{\prime} \cdot$ night $^{-1}$ at 3 and 8 months. The arousal index remained normalized. Diagnostic respiratory disturbance index (RDI) was 60.3 \pm 5.7 events $^{-1} h^{-1}$. On AutoSet at fixed CPAP, RDI was initially $2.6 \pm 0.7$ events $^{\cdot h} h^{-1}$, then rose slightly $(\mathrm{p}<0.001)$ to $4.3 \pm 0.6$ events $\cdot h^{-1}$ at 3 months, and was $3.6 \pm 0.5$ events $\cdot h^{-1}$ at 8 months. AutoSet titration pressure was: $9.9 \pm 0.4 \mathrm{cmH}_{2} \mathrm{O}$ initially, 10.6 \pm 0.4 $\mathrm{cmH}_{2} \mathrm{O}$ at 3 months, and $9.7 \pm 0.5 \mathrm{cmH}_{2} \mathrm{O}$ at 8 months (NS). Manual titration pressure at 8 months was $10.4 \pm 0.4 \mathrm{cmH}_{2} \mathrm{O}$. The standard deviation of the discrepancy with AutoSet was $0.84 \mathrm{cmH}_{2} \mathrm{O}$.

In conclusion, the AutoSet recommended pressure varies little with time, and closely predicts the final manual titration pressure; the improvement in respiratory disturbance index was largely maintained, and compliance was good, although probably enhanced by close supervision.
\end{abstract}

Eur Respir J 1997; 10: 2073-2078.

Nasal continuous positive airway pressure (nCPAP) is the standard treatment for obstructive sleep apnoea (OSA) syndrome. The pressure required to eliminate respiratory events varies widely [1]. Titration, the process of making the trade-off between eliminating all obstructive events by increasing pressure, versus reducing side-effects by using the lowest possible pressure, is a poorly understood, expensive, and time-consuming art.

We have previously reported that the AutoSet selfadjusting nCPAP system produces an excellent reduction in the respiratory disturbance index (RDI), with normalization of the micro-arousal index. and increases in percentage of slow wave and rapid eye movement (REM) sleep. Furthermore, when subjects are retested the next night at a single fixed pressure determined from the AutoSet study, these benefits are maintained [2]. It is not known whether the AutoSet titration can be used in place of a manual titration, for subsequent long-term home therapy with a conventional fixed-pressure CPAP machine.

The aim of this study was to determine whether the AutoSet titration pressure changes over time, and whether the improvement in sleep and breathing is maintain-
*Dept of Pneumology, Ruhrlandklinik, Medical Faculty, University of Essen, Essen, Germany. **ResMed Ltd, North Ryde, Sydney, Australia.

Correspondence: H. Teschler

Ruhrlandklinik

Tüschener Weg 40

D-45239 Essen

Germany

Keywords: AutoSet compliance

nasal continuous airway pressure obstructive sleep apnoea syndrome therapy

Received: June 181996

Accepted after revision April 211997 ed, or if sleep and breathing deteriorate unacceptably once the initial rebound of REM and slow wave sleep is over. An additional observation during the initial study was that AutoSet titration produced a higher pressure than manual titration in which obstructive events, but not snoring, were eliminated. Therefore, we wanted to determine whether AutoSet titration produces a similar pressure to manual titration that aims to eliminate snoring.

\section{Materials and methods}

This study provides follow-up data at 3 and 8 months for a group of 20 subjects, whose characteristics and initial titration results have been described in detail previously [2].

\section{Subjects}

The sample population consisted of subjects referred to the Ruhrlandklinik for assessment of possible sleepdisordered breathing, who met the following criteria: 1) 
either a RDI at home screening (Nellcor EdenTrace ${ }^{\mathrm{TM}}$; Nellcor, Eden Prairie, MN, USA) of at least 20 events $^{-1} h^{-1}$, or a history or finding on home screening of snoring, plus an Epworth sleepiness score of $>10$; 2) living within $1 \mathrm{~h}$ drive of the clinic; and 3) no history of stroke, cardiac failure, transient ischaemic attack, nasal pathology, or daytime respiratory failure. Subjects with nocturnal myoclonus $\left(>5 \pm\right.$ SEM spasms $\left.\cdot \mathrm{h}^{-1}\right)$ at subsequent polysomnography were also excluded. The age of the subjects studied ranged 36-76 yrs (mean \pm SEM $52 \pm 2$ yrs). Body mass index (BMI) ranged $25-48 \mathrm{~kg} \cdot \mathrm{m}^{-2}\left(33.8 \pm 1.3 \mathrm{~kg} \cdot \mathrm{m}^{-2}\right)$. The project was approved by the Ethics Committee of the University of Essen, and informed consent was obtained from each participating subject.

\section{Self-setting device}

Details of the self-setting device have been described previously [2]. Briefly, the device measures mask airflow with a pneumotachograph. The flow signal is further processed to obtain instantaneous leak, respiratory airflow, and snore. Pressure is initially set to $4 \mathrm{cmH}_{2} \mathrm{O}$. The device increases pressure in response to closed airway apnoeas lasting more than $10 \mathrm{~s}$, snoring, and changes in the inspiratory flow-time curve suggestive of inspiratory airflow limitation. A maximum pressure limit of $20 \mathrm{cmH}_{2} \mathrm{O}$ is provided. If no further abnormalities are detected, the pressure slowly decreases to $4 \mathrm{cmH}_{2} \mathrm{O}$.

\section{Study design}

Subjects were studied at the time of the initial titration, again after approximately 3 months of use, and again after a total of approximately 8 months of use. Precise intervals varied depending on subjects and availability of equipment (table 1).

Initial visit. On the first ("diagnostic") night, the diagnosis and severity of OSA were determined. On the "manual" titration night, the critical CPAP pressure was determined by the polysomnographic technician. The critical pressure was the minimum required to eliminate apnoeas and obstructive hypopnoeas in all sleep stages and body positions. There was no attempt to eliminate snoring or airflow limitation. On the "AutoSet" night, the subject slept while using the automatic titration device. The two titration nights (manual and AutoSet) were performed on consecutive nights in random order, and within 5 days of the diagnostic night.

On the fourth, "fixed" pressure night, the subject slept with a conventional CPAP machine set at a fixed pressure determined from the results of the AutoSet night. This pressure was chosen as follows: intervals where total leak calculated by the AutoSet software exceeded 0.4 $\mathrm{L} \cdot \mathrm{S}^{-1}$ were excluded, and the fixed pressure was taken as the pressure that was exceeded during only $5 \%$ of the remaining time. It should be emphasized that the fixed pressure is the pressure exceeded during only $5 \%$ of the time, not $95 \%$ of the peak pressure. In an unrealistic but illustrative example, if the pressure was $4 \mathrm{cmH}_{2} \mathrm{O}$ for $95 \%$ of the AutoSet night, and $20 \mathrm{cmH}_{2} \mathrm{O}$ for the remaining $5 \%$ of the AutoSet night, the chosen pressure for the fixed pressure night would be $4 \mathrm{cmH}_{2} \mathrm{O}$, not $19 \mathrm{cmH}_{2} \mathrm{O}$.
The procedure was performed by an investigator blinded to the results of the manual titration.

The patient was then sent home, where a conventional CPAP machine (Elite; ResMed, Sydney, Australia) was used at the fixed pressure determined at the AutoSet titration. The automatic start/stop feature was employed, so that the hour-meter started when the subject breathed on the mask and stopped when the mask was removed.

Three month follow-up. On the fixed night, the subject slept at home with nCPAP at their previously determined fixed pressure. In addition, they wore the Nellcor EdenTrace $^{\mathrm{TM}}$ ambulatory monitoring system. This device measures oronasal airflow, chest wall impedance, cardiac frequency, oxygen saturation, snoring, and body position. The device has previously been well validated [3] for use without a CPAP mask.

The hour-meter on the CPAP machine was then read. This night was immediately followed by repeat AutoSet and manual titration nights, with full polysomnography in 16 subjects, and with cardiac frequency, respiratory and oximetry data but no sleep staging in four subjects. At the follow-up study, the criteria for the manual titration were changed (according to the German Pneumological Society guidelines) to include abolition of snoring as well as obstructive apnoeas and hypopnoeas, and to be in line with the recommendations of the American Sleep Disorders Association [4]. The patient's fixedpressure home nCPAP machine was then adjusted to the pressure determined by the repeat AutoSet titration.

Eight month follow-up. The procedure at the 8 month follow-up was as described for the 3 month follow-up.

\section{Sleep studies}

Nocturnal polysomnography was performed as described previously [2]. Briefly, standard sleep staging, oronasal thermistors, ribcage and abdominal movement, pulse oximetry, and tibialis anterior electromyographic (EMG) activity were recorded on paper at $10 \mathrm{~mm} \cdot \mathrm{s}^{-1}$.

Polysomnograms were manually scored for episodes of disordered breathing and for changes in arterial oxygen saturation $\left(\mathrm{S}_{\mathrm{a}}, \mathrm{O}_{2}\right)$ using the following criteria: obstructive apnoeas were identified as episodes of absent thermistor signal lasting more than $10 \mathrm{~s}$, and associated movements of the thorax or abdomen. Hypopnoeas were defined as episodes lasting more than $10 \mathrm{~s}$, during which the thermistor signal was reduced to less than $50 \%$ of its magnitude during normal unobstructed breathing and $\mathrm{Sa}_{\mathrm{a}} \mathrm{O}_{2}$ dropped by at least $4 \%$. The numbers of apnoeas and hypopnoeas per hour of sleep were added to determine the RDI. The arousal index was calculated as the number of micro-arousals per hour, using the American Sleep Disorders Association criteria [5, 6].

The Nellcor disposable oronasal thermistor was used for all studies (including the diagnostic study, the inhospital CPAP nights, and the home CPAP (EdenTrace ${ }^{\mathrm{TM}}$ ) studies. On the CPAP nights, it was worn under the CPAP mask. Because it is mounted in a very thin band of adhesive tape, it can be worn under the mask with negligible discomfort or leak. The AutoSet pneumotachograph signal was not used, because it was not available on the diagnostic night or during the home polygraphic studies. 
The home studies were manually scored for apnoeas and hypopnoeas from the paper tracing, using the same criteria as for the in-hospital studies. Since sleep staging was not available, the RDI for home studies was calculated as events $\cdot \mathrm{h}^{-1}$ of study duration.

\section{Statistical analysis}

Comparisons between study nights were made using repeated measures analysis of variance (ANOVA), followed, where the omnibus F-test was significant, by planned linear comparisons using the modified Bonferroni's method [7]. For the RDI, analysis was performed on the rank transformed data. All values are presented as mean \pm between-subject SEM, if not otherwise indicated. To preserve normality and variance homogeneity, the data from the diagnostic night were not included in this analysis. A p-value less than 0.05 was considered significant. Bias and limits of agreement between manual and AutoSet titration were calculated using the method of BLAND and Altman [8].

\section{Results}

\section{Compliance}

No subjects dropped out of the study. Generally, subjects reported nightly use, with the exception of two subjects who did not use the machine for approximately 4 days each, during an upper respiratory tract infection. Average nightly use based on hour-meter readings is presented in table 1 . There was no change in use from 3 to 8 months, and use was very similar to in-laboratory total sleep times.

\section{Titration pressure}

Figure 1 and table 2 show the mean differences between manual and AutoSet titration pressures at the initial visit, at the 3 month follow-up, and at 8 months. There were no important or significant changes in the AutoSet titration pressure with time. At the 8 month follow-up, the AutoSet titration pressure was on average $0.75 \pm 0.2 \mathrm{cmH}_{2} \mathrm{O}$ lower than the manual titration pressure $(\mathrm{p}=0.001)$.

Figure 2 shows the AutoSet titration pressure plotted against the manual titration pressure for each subject at each visit. Inspection of a Bland and Altman plot (fig. 3 ) showed no correlation either between the bias or the scatter and the mean of AutoSet and manual titration pressure. Limits of agreement between the two titration methods are shown in table 2 . The within-subject, with-

Table 1. - Hour-meter readings

\begin{tabular}{lccc}
\hline \multicolumn{2}{c}{$\begin{array}{c}\text { Duration of therapy } \\
\text { days }\end{array}$} & $\begin{array}{c}\text { Usage } \\
\text { h.night }{ }^{-1}\end{array}$ & $\begin{array}{c}\text { TST } \\
\text { h }\end{array}$ \\
\hline 3 month follow-up & $85(55-127)$ & $5.69 \pm 0.12$ & $5.53 \pm 0.08$ \\
8 month follow-up & $244(154-479)$ & $5.72 \pm 0.11$ & $5.77 \pm 0.08$ \\
\hline
\end{tabular}

Data are presented as mean, and range in parenthesis or as mean \pm SEM. Duration of therapy: time between initiation of therapy and follow-up; Usage: hour-meter reading divided by duration of therapy; TST: total sleep time at polysomnography (averaged over next two nights in hospital). There was no deterioration in compliance with the passage of time. TST was closely equated to the daily usage.

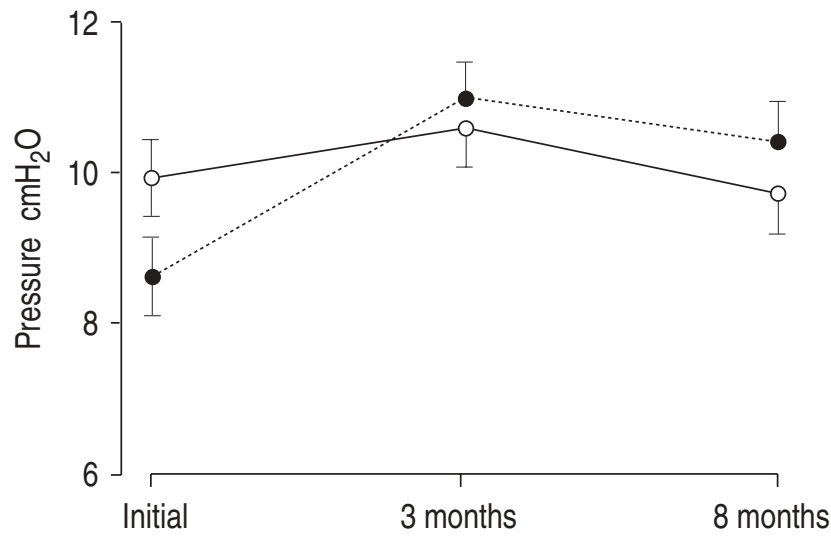

Fig. 1. - Titration pressure on initial titration, and at 3 month and at 8 month follow-up. —_ - : AutoSet titration, 95th centile pressure during periods with leak less than $0.4 \mathrm{~L} \cdot \mathrm{s}^{-1} ; \_\_$: manual titration, for initial visit, obstructive apnoeas and hypopnoeas were eliminated; on subsequent titrations snoring was also eliminated. The mean AutoSet titration pressures did not change with time. As expected, the manual titration pressure on the first visit was lower than either the AutoSet pressure $(\mathrm{p}<0.001)$, or the subsequent manual titration pressures $(\mathrm{p}<0.001)$. Error bars are within-subject $95 \%$ confidence intervals.

in-visit root mean square (RMS) deviation for the AutoSet titration pressure and manual titration pressure are also presented in table 2.

One patient complained of rhinitis and a blocked nose at the 3 month titration. His AutoSet titration pressures at 0,3 and 8 months were $6.5,10.0$ and $7.0 \mathrm{cmH}_{2} \mathrm{O}$, respectively. The manual titration at 3 months was performed after nasal decongestant, and yielded a pressure of $8.5 \mathrm{cmH}_{2} \mathrm{O}$.

Mean body weight fell slightly, from $110 \pm 4 \mathrm{~kg}$ initially, to $109 \pm 4$ and $104 \pm 4 \mathrm{~kg}$ at 3 and 8 months, respectively (NS).

During the initial study, when the technician titrated to eliminate apnoeas and hypopnoeas, but not snoring, the AutoSet pressure was higher on average by 1.3 $\mathrm{cmH}_{2} \mathrm{O}(\mathrm{p}=0.001)$. At the 3 and 8 month studies, when manual titration aimed to eliminate snoring as well as obstructive apnoeas and hypopnoeas, the relationship was closer (AutoSet on average 0.4 and $0.7 \mathrm{cmH}_{2} \mathrm{O}$, respectively, below manual titration). The standard deviation of the discrepancy between AutoSet and manual titration at the initial study was $1.2 \mathrm{cmH}_{2} \mathrm{O}$, and 1.1 and $0.8 \mathrm{cmH}_{2} \mathrm{O}$ at 3 and 8 months follow-up, respectively.

Table 2. - Titration pressure on initial titration, at 3 months and at 8 months

\begin{tabular}{lcccc}
\hline & \multicolumn{4}{c}{ Titration pressure $\mathrm{cmH}_{2} \mathrm{O}$} \\
\cline { 2 - 5 } & Initial & 3 months & 8 months & $\begin{array}{c}\text { Reproduci- } \\
\text { bility }\end{array}$ \\
\hline AutoSet & $9.9 \pm 0.4$ & $10.6 \pm 0.4$ & $9.7 \pm 0.5$ & 1.17 \\
Manual & $8.6 \pm 0.4^{+++}$ & $11.0 \pm 0.5^{* * *}$ & $10.4 \pm 0.4^{* * * *}$ & 1.14 \\
Bias & 1.3 & -0.4 & -0.6 & \\
Limits of & \pm 2.5 & \pm 2.3 & \pm 1.8 & \\
agreement & & & & \\
\hline
\end{tabular}

Data are presented as mean \pm SEM. AutoSet: 95th centile pressure during periods with leak $<0.4 \mathrm{~L} \cdot \mathrm{s}^{-1}$; manual: for initial visit, pressure manually determined to eliminate obstructive apnoeas and hypopnoeas; for subsequent visits, snoring was also eliminated; Bias: mean difference between manual and AutoSet for a given visit; Reproducibility: within-subject, within-time root mean square (RMS) deviation. ***: $\mathrm{p}<0.001$, versus initial; $\mathrm{p}=0.03$, versus AutoSet; ${ }^{++}: \mathrm{p}<0.001$, versus AutoSet. 

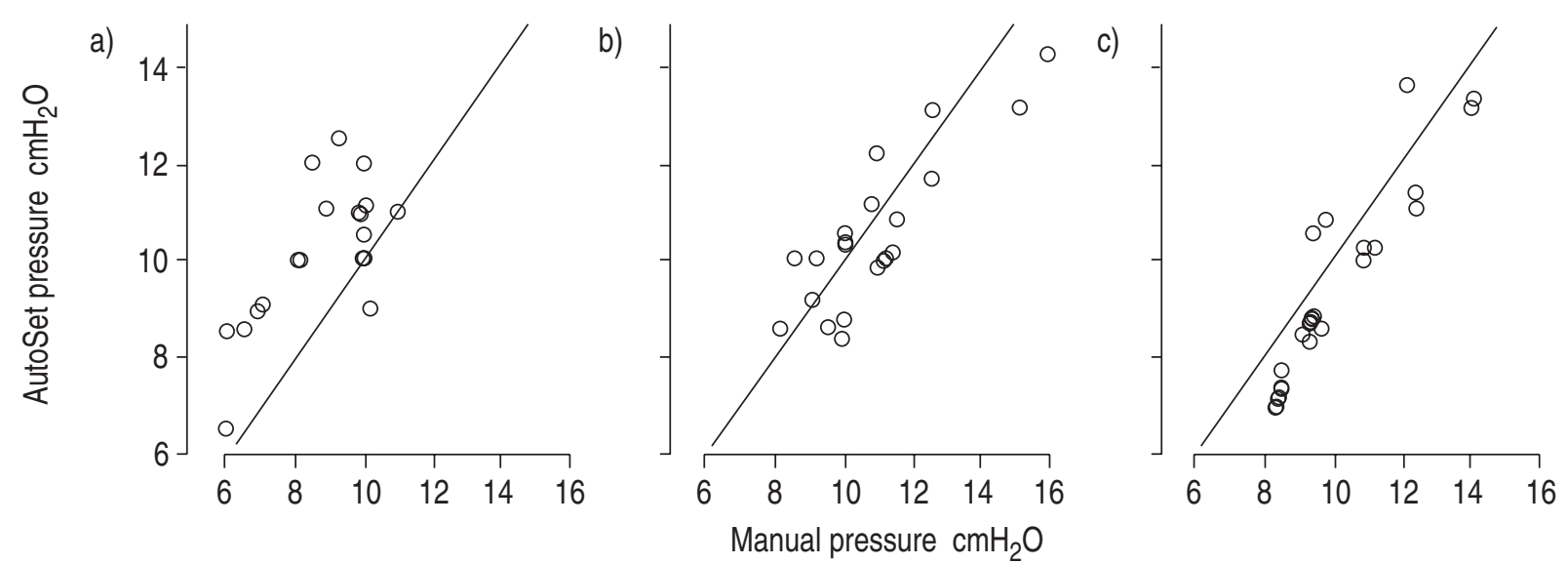

Fig. 2. - AutoSet titration pressure versus manual titration pressure, with line of identity: a) initial study; b) 3 month follow-up; c) 8 month follow-up.
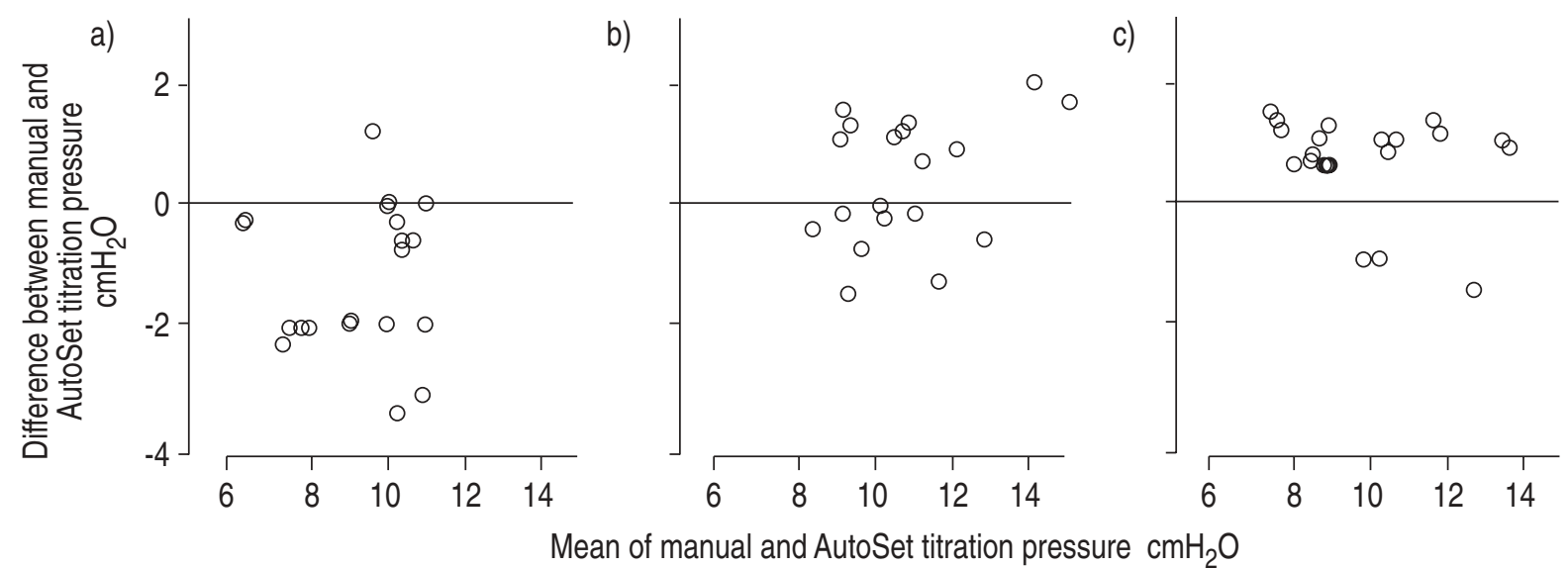

Fig. 3. - Bland and Altman plot of difference between manual titration pressure and AutoSet titration pressure, plotted against the mean of the manual and AutoSet titration pressure: a) initial study; b) 3 month follow-up; c) 8 month follow-up.

\section{Respiratory disturbance index}

RDIs results are presented in table 3. With the exception of the initial manual titration night, the RDI remained very low compared with the diagnostic night. On the initial manual titration, two subjects had ongoing central apnoeas, so that the mean value was not representative of the other subjects. The RDI at home on fixed pressure at 3 and 8 months was higher than at the initial AutoSet and fixed nights in hospital $(\mathrm{p}<0.001)$, but the results were still very acceptable (on average only

Table 3. - Respiratory disturbance index (RDI) on diagnostic night, on AutoSet, during manual titration, and at the fixed pressure determined from the AutoSet titration

\begin{tabular}{lrll}
\hline & \multicolumn{3}{c}{ RDI events $\mathrm{h}^{-1}$} \\
\cline { 2 - 4 } & \multicolumn{1}{c}{ Initial } & 3 months & 8 months \\
\hline Diagnostic & $60.3 \pm 5.7$ & & \\
AutoSet & $2.8 \pm 0.9$ & $3.2 \pm 0.7$ & $3.3 \pm 0.5$ \\
Manual & $10.1 \pm 3.0$ & $4.3 \pm 0.5$ & $4.3 \pm 0.3$ \\
Fixed & $2.6 \pm 0.7$ & $4.3 \pm 0.6^{* * *}$ & $3.6 \pm 0.5^{* * *}$ \\
\hline
\end{tabular}

All studies are in hospital with full polysomnography, with the exception of the fixed nights at 3 and 8 months, which are at home using Nellcor ambulatory monitoring. There were no important or significant differences in RDI between the three AutoSet nights. Probability values are on rank transformed data. $* * *: \mathrm{p}<0.001$, versus initial fixed night.
7 and $6 \%$ of the untreated value, respectively), and the RDI at home was very comparable to the RDI on retitration, either manually or with AutoSet.

\section{Sleep architecture}

Sleep quality results are presented in table 4. Differences amongst the four initial studies have been described previously [2]. Briefly, the three initial treatment nights showed a rebound in the percentage of slow wave and REM sleep, and a normalization of the arousal index.

Follow-up versus initial diagnostic study. The percentage of time in light (stages I-II) non-REM sleep was still markedly reduced, and time in slow wave and REM sleep increased. The arousal index remained normalized. There were no important differences between results at 3 and 8 months.

Follow-up versus initial AutoSet study. The percentage of time in stages I and II non-REM sleep had increased, and there were corresponding minor reductions in the percentages of slow wave and REM sleep compared with the initial AutoSet study, although these reductions did not reach statistical significance $(p>0.05)$. There was a significant reduction in the percentage of time awake compared with the original AutoSet study. 
Table 4. - Sleep quality at initial visit, and at 3 and 8 months follow-up

\begin{tabular}{|c|c|c|c|c|c|c|}
\hline & $\begin{array}{l}\text { Wake } \\
\% \text { TIB }\end{array}$ & $\begin{array}{c}\text { TST } \\
\mathrm{h}\end{array}$ & $\begin{array}{l}\text { Stage I+II } \\
\% \text { TIB }\end{array}$ & $\begin{array}{c}\text { Stage III+IV } \\
\% \text { TIB }\end{array}$ & $\begin{array}{l}\text { REM } \\
\% \text { TIB }\end{array}$ & $\begin{array}{c}\text { AI } \\
\text { events } \cdot h^{-1}\end{array}$ \\
\hline \multicolumn{7}{|l|}{ Initial $^{\ddagger}$} \\
\hline Diagnostic & $3.0 \pm 0.6$ & $5.9 \pm 0.08$ & $74.8 \pm 3.3$ & $8.6 \pm 2.2$ & $10.5=$ & $53.9 \pm 4.6$ \\
\hline Manual & & & & & & \\
\hline $\mathrm{Au}$ & 7 & & & & & 0.9 \\
\hline $\begin{array}{l}\text { Fixed } \\
3 \text { month }\end{array}$ & 5.5 & $6.0 \pm 0.07$ & 4 & & 10 & $9.1 \pm 1.0$ \\
\hline Autc & $5^{++}$ & 6 & $3^{++}$ & 0 & 19. & 10 \\
\hline $\begin{array}{l}\text { Fixed } \\
8 \text { months }\end{array}$ & $3.7=$ & $5.4=$ & 5 & .8 & 17. & \pm 0.7 \\
\hline AutoSet & $3.3 \pm 0.3^{++}$ & $5.9 \pm 0.06$ & & & $18.3 \pm 0.8$ & $8.8 \pm 0.7$ \\
\hline He & $3.9=$ & $5.6 \pm 0.13$ & 1.8 & 21.5 & $18.7 \pm 0.9$ & $11.0 \pm 0.5$ \\
\hline Pooled SEM & 0. & 0.1 & 2 & 23 & 1.4 & 2.4 \\
\hline
\end{tabular}

Data are presented as mean \pm SEM. TIB: time in bed; TST: total sleep time; REM: rapid eye movement sleep; AI: arousal index; Pooled SEM: within-subject pooled standard error of mean. + differences amongst the four initial studies are described elsewhere; ${ }^{++}: \mathrm{p}<0.002$, significantly different from initial AutoSet study; ${ }^{\dagger}$ : apart from trivial differences between total sleep times, there were no significant differences between values at 3 and 8 months.

\section{Discussion}

The present study demonstrates that, when assessed by an objective autotitrating method, AutoSet titration pressure in a given subject was reproducible, and there was no change in the titration pressure requirement from initial titration to 3 or 8 months. The RDI measured at home remained very satisfactory. Normalization of arousal index was maintained. The improvement in sleep architecture was maintained, even after the rebound of REM and slow wave sleep was over. Finally, manual titration to eliminate snoring required a higher pressure than titration to eliminate obstructive apnoeas and hypopnoeas.

\section{Compliance}

Compliance was very good and stable, with values similar to those reported in the literature [9-12]. Although previous studies have shown that hour-meter readings can overestimate actual hours of use $[12,13]$, the CPAP machine used in the present study has an automatic start/stop feature, which makes it extremely difficult for the subject to run the blower without actually wearing it, so that hours logged should equal hours used. However, the subjects volunteered for a complex protocol, and were likely to be highly motivated. Therefore, these results will not extrapolate directly to the general population of CPAP users, who may experience lower compliance and higher drop-out.

\section{AutoSet titration pressure}

The within-subject, within-time RMS deviation of the AutoSet titration pressure was $1.2 \mathrm{cmH}_{2} \mathrm{O}$, accounting for $27 \%$ of the total variance in pressure. Changes in nasal resistance influence pressure requirement [14], and some of the $1.2 \mathrm{cmH}_{2} \mathrm{O}$ variability will have been due to genuine random transient changes in requirement, as seen in the subject with a viral infection at 3 months, and random changes in sleep position [15] and sleep stage distribution probably account for further variability.

It is a commonly held belief that pressure requirement decreases with time because factors such as traumatic upper airway oedema and REM duration would be expected to reduce with time [16]. Consequently, it has been our routine practice to retitrate at 3 months. SÉRIES et al. [17] have reported a decrease in manual titration pressure of the order of $20 \%$ in a prospective study. Surprisingly, in the present study, the titration pressure was fairly constant from the initial visit to 3 and 8 months follow-up. It is possible that the effect of oedema, duration of REM, etc. on titration pressure might depend on the exact end-point used in titration, and this will differ from study to study. For example, one might speculate that, if the closing pressure reduces with time but the nasal resistance remains high, then the pressure needed to eliminate apnoeas may decrease, but the pressure needed to eliminate silent inspiratory airflow limitation may not. Also, knowledge by the technician that the second study is a retitration could influence the results of a manual, but not an automated, titration. Weight reduction has been observed to be associated with a reduction in titration pressure $[18,19]$. The $6 \mathrm{~kg}$ mean reduction in body weight in the present study is, therefore, in the wrong direction to explain the observed lack of reduction in titration pressure.

\section{Relationship between manual and AutoSet titration pres- sures}

We had previously suggested [2] that the slightly higher AutoSet titration pressure compared with manual titration at the initial visit was because the manual titration did not attempt to eliminate snoring. In this study, snoring was eliminated during manual titration at the 3 and 8 month follow-up. This produced on average a 2.2 $\mathrm{cmH}_{2} \mathrm{O}$ increase in the manual titration pressure, with manual pressure now slightly higher than AutoSet pressure. Hence, the exact end-point used in the manual titration will influence the relationship between manual and automatic titration pressure.

\section{Sleep architecture}

As described previously [2], at initial titration, there was, on average, a dramatic increase in percentage of slow wave and REM sleep, and an arousal index of approximately 10 events $\cdot \mathrm{h}^{-1}$. This is in the normal range reported by Mathur and Douglas [20]. Results at 3 and 8 months continued to show great improvement in sleep quality compared with the diagnostic night, and the arousal index remained normalized, but there was an increase in the percentage of light stage I-II non-REM sleep, consistent with return to normal sleep architecture after resolution of the initial slow wave and REM sleep rebound. It would be interesting to compare sleep architecture with normal values for age-matched controls using long-term CPAP, but we are aware of no such data. At the original AutoSet titration, there was an increase in the percentage of time awake compared 
with manual titration. This was not the case for the subsequent AutoSet studies. This is probably because, at the initial study, AutoSet titration was presented to patients and staff as an experimental procedure, so that patients may have been more anxious, and the technicians also entered the patients' rooms more often.

\section{Respiratory disturbance index}

The RDI recorded at home at 3 months after the first titration was, on average, $7 \%$ of control, and at 8 months (i.e. 5 months after the second titration) it was $6 \%$ of control, confirming that treatment remained adequate for at least 5 months following AutoSet titration. On all treatment nights, the oronasal thermistors were placed under the CPAP mask. This could give a different relationship between temperature signal and respiratory airflow, either increasing or decreasing the measured RDI. However, such an effect should not have influenced the relationship between the RDI on CPAP at 0,3 and 8 months. The ambulatory monitoring system used the same transducers as used for the in-hospital study, and respiratory scoring was performed manually, using the same criteria in each case, so that total event counts would be expected to be comparable [3]. The ambulatory system did not record sleep data. If sleep efficiency was low in the home studies, the RDI might be underestimated. However, the equipment was considerably less intrusive than full polysomnography, where sleep effciency was high, and subjects had had previous experience with the ambulatory monitoring system. Consequently, there was little reason to believe that reduced sleep efficiency would have caused underestimation of the RDI in the home studies.

The RDI at home at 3 and 8 months (4.3 and 3.6 events $\left.\cdot \mathrm{h}^{-1}\right)$ was very comparable to that during manual titration or with AutoSet titration. However, it was substantially more than on either AutoSet or fixed pressure at the first visit (2.8 and 2.6 events $\cdot \mathrm{h}^{-1}$, respectively). This cannot be explained by the hypothesis that titration pressure falls with time. It is more likely that the lower RDI at the initial study reflects the slow-wave rebound. After normalization of sleep architecture, there is more stage I-II sleep, where breathing is more irregular [21].

\section{Conclusion}

In adult subjects with uncomplicated obstructive sleep apnoea syndrome, there is no evidence of a change in pressure requirement at 3 or 8 months when titrating with an automated, objective method (with the end-point being the elimination of snoring, and flattening of the inspiratory flow-time curve). AutoSet titration results in a fixed pressure prescription, which is reproducible and comparable to that produced by manual titration (with the end-point being the elimination of snoring). This pressure yields excellent improvement in sleep-disordered breathing and sleep architecture, which is maintained at 3 and 8 months. Compliance following AutoSet titration was good, but may have been enhanced by the intensive follow-up. The above results taken together support the notion that AutoSet titration can be used in place of manual titration.

\section{References}

1. Sullivan CE, Issa FG, Berthon-Jones M, Eves L. Reversal of obstructive sleep apnoea by continuous positive airway pressure applied through the nares. Lancet 1981; i: 862-865.

2. Teschler H, Berthon-Jones M, Thompson AB, Henkel A, Henry A, Konietzko N. Automated continuous positive airway pressure titration for obstructive sleep apnea syndrome. Am J Respir Crit Care Med 1996; 154: 734-740.

3. Redline S, Tosteson T, Boucher MA, Millman RP. Measurement of sleep-related breathing disturbances in epidemiological studies: assessment of the validity and reproducibility of a portable monitoring device. Chest 1991; 100: 1281-1286.

4. American Thoracic Society. Indications and standards for use of nasal continuous positive airway pressure (CPAP) in sleep apnea syndromes. Am J Respir Crit Care Med 1994; 150: 1738-1745.

5. Rechtschaffen A, Kales AA. Manual of standardized terminology, techniques and scoring system for the sleep stages of human subjects. National Institute of Health. Publication No. 204, U.S. Government Printing Office, Washington, DC, 1968.

6. American Sleep Disorders Association. EEG arousals: scoring rules and examples. Sleep 1992; 15: 174-184.

7. Keppell G. In: Design and Analysis. New Jersey, Prentice Hall, 1982; p. 147.

8. Bland JM, Altman DG. Statistical methods for assessing agreement between two methods of clinical measurement. Lancet 1986; 1: 307-310.

9. Engelman HM, Martin SE, Douglas NJ. Compliance with CPAP therapy with the sleep apnoea/hypopnea syndrome. Thorax 1994; 49: 263-266.

10. Krieger J. Long-term compliance with nasal continuous positive airway pressure (CPAP) in obstructive sleep apnea patients and nonapneic snorers. Sleep 1992; Suppl. 6: 42-46.

11. Rolfe I, Olson LG, Saunders NA. Long-term acceptance of continuous positive airway pressure in obstructive sleep apnea. Am Rev Respir Dis 1991; 144: 1130-1133.

12. Reeves-Hoché MK, Meck R, Zwillich CW. Nasal CPAP: an objective evaluation of patient compliance. Am J Respir Crit Care Med 1994; 149: 149-154.

13. Saunders MH, Kern N. Obstructive sleep apnea treated by independently adjusted inspiratory and expiratory positive airway pressure via nasal mask. Chest 1990; 98: 317-324.

14. McNicholas WT, Tarlo S, Cole P, et al. Obstructive apneas during sleep in patients with seasonal allergic rhinitis Am Rev Respir Dis 1982; 126: 625-628.

15. George CF, Millar TW, Kryger MH. Sleep apnea and body position during sleep. Sleep 1988; 11: 90-99.

16. Sullivan CE, Grunstein RR. Continuous positive airways pressure in sleep-disordered breathing. In: Kryger MH, Roth T, Dement WC, eds. Principles and Practice of Sleep Medicine. Philadelphia, W.B. Saunders, 1989; pp. 559-570.

17. Sériès F, Marc I, Cormier Y, La Forge J. Required levels of nasal continuous positive airway pressure during treatment of obstructive sleep apnoea. Eur Respir J 1994; 7: 1776-1781.

18. Bray GA. Barriers to the treatment of obesity. Ann Intern Med 1985; 103: 850-855.

19. Harman EM, Wynn JW, Block AJ. The effect of weight loss on sleep-disordered breathing and on oxygen desaturation in morbidly obese men. Chest 1982; 82: 291-294.

20. Mathur R, Douglas NJ. Frequency of EEG arousals from nocturnal sleep in normal subjects. Sleep 1995; 18: 330-333.

21. Krieger J. Breathing during sleep in normal subjects. Clin Chest Med 1985; 6: 577-594. 